\title{
Cartografiar los espacios de relación: la cartografía y el foto-ensayo como instrumento de indagación colectiva
}

\section{Mapping Relationship Spaces: Cartography and Photo-Essay as a Collective inquiry Instrument}

\author{
Estibaliz Aberasturi Apraiz \\ Universidad del País Vasco (UPV/EHU) \\ estitxu.aberasturi@ehu.eus
}

\begin{abstract}
Alaitz Sasiain Camarero-Nuñez
Universidad del País Vasco (UPV/EHU)

alaitz.sasiain@ehu.eus
\end{abstract}

\section{Aingeru Gutierrez-Cabello Barragán \\ Universidad del País Vasco (UPV/EHU) \\ aingeru.gutierrez-cabello@ehu.eus \\ Jose Miguel Correa Gorospe \\ Universidad del País Vasco (UPV/EHU) \\ jm.correagorospe@ehu.eus}

Recibido: 13/09/2020 Revisado: 18/10/2020

Aceptado: 09/12/2020 Publicado: 14/12/2020

\section{Resumen}

En este artículo se muestra un estudio visual donde indagamos acerca de cómo nos relacionamos con los espacios en nuestra facultad y qué otras relaciones podríamos provocar a partir de la reflexión conjunta. El marco metodológico elegido es la Investigación Basada en las Artes. Los resultados son imágenes que parten de las

Sugerencias para citar este artículo:

Aberasturi Apraiz, Estibaliz; Sasiain Camarero-Nuñez, Alaitz; Gutierrez-Cabello Barragán, Aingeru y Correa Gorospe, Jose Miguel (2020). Cartografiar los espacios de relación: la cartografía y el fotoensayo como instrumento de indagación colectiva. Tercio Creciente (Monográfico extraordinario IV), (pp. 33-46), https://dx.doi.org/10.17561/rtc.extra4.5743

ABERASTURI APRAIZ, ESTIBALIZ; SASIAIN CAMARERO-NUÑEZ, ALAITZ; GUTIERREZCABELLO BARRAGÁN, AINGERU y CORREA GOROSPE, JOSE MIGUEL. Cartografiar los espacios de relación: la cartografía y el foto-ensayo como instrumento de indagación colectiva. Tercio Creciente (Monográfico extraordinario IV), diciembre 2020, pp. 33-46, https://dx.doi.org/10.17561/rtc.extra4.5743 
producciones audiovisuales obtenidas a partir de las cartografías realizadas por los participantes en distintos talleres. Las producciones visuales realizadas nos permiten abrir nuevos interrogantes acerca de cómo resignificar el espacio social de la propia facultad. Este trabajo contribuye a explorar las siguientes preguntas de investigación ¿Es posible abordar un inicio de proyecto a través de estrategias heredadas de las artes visuales? ¿Se puede pensar o generar un discurso con el empleo de la imagen? Las conclusiones de este proyecto se basan en un foto-ensayo que reflexiona sobre el trabajo desarrollado y reflexiona sobre los resultados obtenidos en el taller de las cartografías.

\section{Abstract}

This article is based on a visual study where we try to inquiry about how we relate with the different spaces of our Faculty and which other relations we can stablish with them. The methodological approach chosen to conduct this project is the art-based research. The audio-visual productions derived from the cartographies developed by the participants in different workshops, conform the results of the research. Their visual productions allow us to open new questions about how to give new meanings to the social spaces of the Faculty. This work contributes to make these research questions, Can we understandls it possible to develop a research through visual art strategies? Can we build new discourses using images? The conclusions of this project are based on a photo-essay which reflects about the results obtained in the cartographic workshops.

\section{Palabras clave / Keywords:}

Metodologías basadas en las artes, formación del profesorado, indagación narrativa, cartografía / Art-based research, teachers training, narrative inquiry, cartography.

\section{Sugerencias para citar este artículo:}

Aberasturi Apraiz, Estibaliz; Sasiain Camarero-Nuñez, Alaitz; Gutierrez-Cabello Barragán, Aingeru y Correa Gorospe, Jose Miguel (2020). Cartografiar los espacios de relación: la cartografía y el fotoensayo como instrumento de indagación colectiva. Tercio Creciente (Monográfico extraordinario IV), (pp. 33-46), https://dx.doi.org/10.17561/rtc.extra4.5743

ABERASTURI APRAIZ, ESTIBALIZ; SASIAIN CAMARERO-NUÑEZ, ALAITZ; GUTIERREZCABELLO BARRAGÁN, AINGERU y CORREA GOROSPE, JOSE MIGUEL. Cartografiar los espacios de relación: la cartografía y el foto-ensayo como instrumento de indagación colectiva. Tercio Creciente (Monográfico extraordinario IV), diciembre 2020, pp. 33-46, https://dx.doi.org/10.17561/rtc.extra4.5743 


\section{Contextualización:}

La experiencia que relatamos en este trabajo forma parte del proyecto de innovación docente "Facultad de Educación de Bilbao: Resignificar el Espacio Social" de la convocatoria Bizkai Campus Lab (CNL) (19PEZA).

En este artículo nos hemos detenido a explorar aquellos significados y afectos que emergen del trabajo cartográfico desarrollado junto a profesores universitarios, alumnado y personal administrativo acerca de su propia Facultad. Los siguientes apartados recogen una experiencia de indagación colaborativa a través de métodos artístico-visuales y narrativos, donde nuestro relato como investigadores forma parte de un elemento más dentro del ensamblaje de voces, imágenes y subjetividad que se desprende de lo experimentado en los talleres. Detenernos a pensar colectivamente sobre los espacios por los que transitamos diariamente, nos permite desnaturalizar las lógicas que guardan y los afectos que producen, conduciéndonos a repensar políticamente nuevas formas de convivencia dentro de los espacios sociales de la Facultad.

\section{Introducción}

Para esta experiencia de investigación nos preguntamos cómo nos relacionamos con los espacios y qué otras relaciones podríamos provocar. Esta pregunta la ponemos en relación con un proyecto de innovación que durante el curso 2019-20 participamos en el diseño y desarrollo de un taller de investigación cartográfica dentro de la Facultad de Educación (Campus de Bizkaia) de la Universidad del País Vasco (UPV/EHU). La motivación por desarrollar el taller se vinculaba al segundo objetivo donde partíamos del deseo por pensar colectivamente acerca de cómo nos relacionamos con los espacios de la facultad y explorar qué otras relaciones podríamos provocar a partir de esta clase de reflexiones compartidas. Para ello, participamos en la elaboración de un taller formativo basado en la hibridación entre un conocimiento proveniente de los cartógrafos, que la investigación basada en las artes la incorpora a su proceso de búsqueda creativo y especulativo. Partíamos de la hipótesis de que adoptar métodos de investigación basadas en las artes (Gutiérrez-Cabello y Aberasturi, 2019) nos permitiría desvelar nuevos matices ocultos en torno a los modos de relacionarnos con el espacio de la Facultad. Trabajar con mapas artísticos nos permitía no reproducir un inconsciente cerrado sobre sí mismo, sino representar conceptos clave de forma abierta, alterable, susceptible de recibir constantemente modificaciones, ofreciéndonos un espacio para 
la reflexión compartida rica en matices no esperados. "La cartografía puede romperse, alterarse, adaptarse a distintos montajes, ser iniciado por un individuo, un grupo, una formación social. Puede dibujarse en una pared, concebirse como una obra de arte, construirse como una acción política o como una meditación" (Deleuze y Guattari, 2008, p. 29).

Este artículo basado en el foto-ensayo se sitúa en la primera fase del proyecto en el que nos planteamos trazar colectivamente mapas de lo posible, que nos ayudasen a proponer nuevas estrategias pedagógicas y relaciones en el contexto de la Facultad, reflexionando sobre problemáticas que nos afectaban. Repensar el espacio donde trabajamos y en cómo afectan esos espacios en las relaciones pedagógicas ha sido uno de los objetivos planteados para el taller en el que participamos. Estamos ante espacios que han sido pensados para transitar y no habitar. De hecho, el desarrollo de la arquitectura, tal y como nos recuerda el autor Pallasmaa (2006), lo sostienen fuerzas y modelos de gestión, organización y producción que universalizan una determinada racionalidad tecnológica. Algo, sin embargo, que nos moviliza a cuestionar sus sentidos y a preguntarnos, ¿cómo cambiar un espacio? ¿cuáles son las necesidades de quienes transitan dicho lugar?, ¿Cómo lo habitamos?, ¿Cómo lo vivimos?, ¿Cómo volvemos a colocar el cuerpo en el centro del mundo de la experiencia?

\section{Desarrollo: El taller cartográfico cómo medio para comenzar}

Para el desarrollo de nuestra propuesta, elaboramos un taller donde invitamos a las participantes a traer 3 imágenes que relacionasen a la pregunta: ¿cómo afecta el espacio social que habitamos en nuestros modos de relación? A partir de la conversación grupal emergieron conceptos e ideas clave que cada participante utilizó para elaborar su propio mapa. Propusimos un taller donde abordar desde las cartografías otras formas de indagación más creativas. Un método de trabajo que nos permitiese pensar y reflexionar sobre la temática a abordar. Una forma diferente de producir conocimiento (St. Pierre, 1997). La comunicación realizará un recorrido visual de la experiencia, colocando el foco precisamente en este conocimiento emergente, que nos permite desde lo artístico establecer recorridos abiertos a otras posibilidades. Coincidimos con Fernández y Genet (2008, p. 39) que "en esta forma de estudio tanto la obtención de datos como la presentación de resultados se realizarán mediante fotografías, estando encargadas de enunciar, desarrollar y concluir el discurso". 


\subsection{Antecedentes:}

Durante el año 2015 desde nuestro grupo de investigación Elkarrikertuz (IT88716) de la Universidad del País Vasco (UPV/EHU) junto al grupo Esbrina (2017 SGR 1248) de la Universidad de Barcelona, participamos en el proyecto denominado "APREN-DO: Cómo aprenden los docentes implicaciones educativas y retos para afrontar el cambio social“ (ED2015-70912-C2-1-R) donde trabajamos con metodologías cartográficas para obtener datos y comprender mejor las trayectorias y vivencias del profesorado que participó en la investigación. Este proceso de investigación, nos ha permitido transitar de un método de investigación a una propuesta de formación, donde resignificar de una forma más abierta y creativa, aquello que nos preguntamos o sobre lo que queramos reflexionar.

La cartografía por sus características físicas y conceptuales es un medio para poder abordar una pregunta de investigación de un modo más intuitivo, personal e inconsciente permitiendo al investigador pensar a través de ella. Lo cartográfico, tal y como sugiere Braidotti (2018), se transforma en un objeto discursivo que contribuye al intercambio dialógico. La conversación que se inicia a partir de cada producción artística ayuda a establecer nuevos ensamblajes nómadas, donde lo humano y no humano, lo material y lo simbólico acaban por enredarse.

\subsection{Objetivos, Metodologías y Temporalización: La creación cómo metodología de investigación}

Para poder comenzar es necesario partir de una pregunta o un enunciado el cual te pone en situación. Cuando la pregunta es lo suficientemente abierta y a la vez concreta de manera intuitiva te permite comenzar a trabajar, surge la necesidad de dibujar, conectar conceptos o corporeizar sensaciones a través de objetos, materiales, mapas o imágenes que evocan esa idea que intentamos abordar. "El objeto artístico da cabida a múltiples interpretaciones que amplían su significación y nos llevan hacia otras preguntas con las que seguir investigando" (Peña, 2014, p. 28). Desde hace tiempo que nuestra comunidad hemos entendido que únicamente trabajando desde las metodologías visuales y basadas en las artes propiciamos la emergencia de conexiones nuevas e inesperadas (Gutiérrez-Cabello y Aberasturi, 2019), contribuyendo así a que puedan surgir esas nuevas ideas que otros enfoques de trabajo tanto dificultan encontrar. 
En cuanto al empleo de la imagen como herramienta discursiva Fernández y Genet citan a Foster (2005, p. 92) "La imagen es a los estudios visuales lo que el texto era a la crítica posestructuralista: una herramienta analítica que ha revelado el artefacto cultural de nuevas maneras, especialmente atendiendo a posicionamientos de diferentes observadores" (2008, p.41). Coincidimos con Cahnmann-Taylor citado por Fernández y Genet (2017, p. 42) que "En la medida en que las imágenes crecen de forma exponencial en nuestras vidas (...) el poder de lo visual tiene implicaciones para todos los investigadores cualitativos" (2008, p. 101).

El marco metodológico que orienta este trabajo es la Investigación Basada en las Artes Visuales (Visual Arts Based Educational Research) (Marín, 2005; Marín y Roldan, 2008,2010; Calderón y Hernández, 2019) que queda englobado dentro de la investigación Educativa Basada en las Artes (Arts Based Educational Research) (Eisner y Barone, 2006). Para llevar a cabo la investigación hemos contado con audios, cartografías, fotografías, notas de campo y conversaciones que han derivado del trabajo en los talleres. Se trata de una investigación de carácter cualitativo que tiene como herramienta de investigación la cartografía, el relato visual que adquieren las cartografías nos sirve para "conectar imágenes, insertar ideas o mapear deseos que hablasen" (Gutiérrez-Cabello y Aberasturi, 2019, p.102) sobre cómo resignificar el espacio social de la propia facultad. La cartografía cómo "un medio para explorar una realidad demasiado compleja para ser categorizada en rígidos sistemas cerrados" (Gutiérrez-Cabello y Aberasturi, 2019, p.102). Gutiérrez-Cabello y Aberasturi reflexionan sobre cómo la investigación Educativa Basada en las Artes puede influir en el investigador:

La apertura de generar otras formas de construir los datos nos hacía asumir, además sus posibles orígenes diversos, asumiendo que no solamente pueden surgir de las transcripciones, observaciones o notas de campo, sino también de los propios sueños, en el cuerpo, o la memoria (St.Pierre, 2017) del investigador (2019, p.102).

En cuanto a la temporalización del taller de cartografía: Para poder comenzar la primera sesión, previamente, se les instó traer al menos tres imágenes y un breve texto, que reflejaran como entienden ellos/as su espacio de trabajo. Para iniciar el taller partimos de la pregunta ¿Cómo afecta el espacio social en mis modos de relación? El 
taller se dividió en dos tiempos. En el primer tiempo (que duró aproximadamente una hora y media), los participantes en grupos más reducidos, dialogaron sobre las imágenes traídas por las compañeras, pero en vez de comentar cada cual su imagen se analizaron las imágenes de los demás desmontando el discurso que cada cual traía consigo y observando de qué modo era analizada la imagen por el resto de los/las compañeros/as generando nuevos conexiones y narraciones sobre el contenido de las imágenes. En cada grupo había un interlocutor el cual transmitía al resto de los grupos las ideas generales que habían surgido en su grupo a modo de síntesis. Todo ello bajo el objetivo de querer comenzar a reflexionar sobre el espacio de trabajo, bajo la pregunta ¿Qué espacios de relación de la facultad te afectan y que relaciones estableces?

En la segunda parte del taller, (aproximadamente 2 horas) manteniendo los mismos grupos, se realizaron las cartografías. Finalmente, en el último periodo del taller, cada grupo expuso el sentido simbólico de cada elemento en el mapa que había elaborado. Cada exposición contribuía a activar nuevos interrogantes e ideas que permitiesen conectar con experiencias personales o con formas distintas de interpretar los espacios de la Facultad.
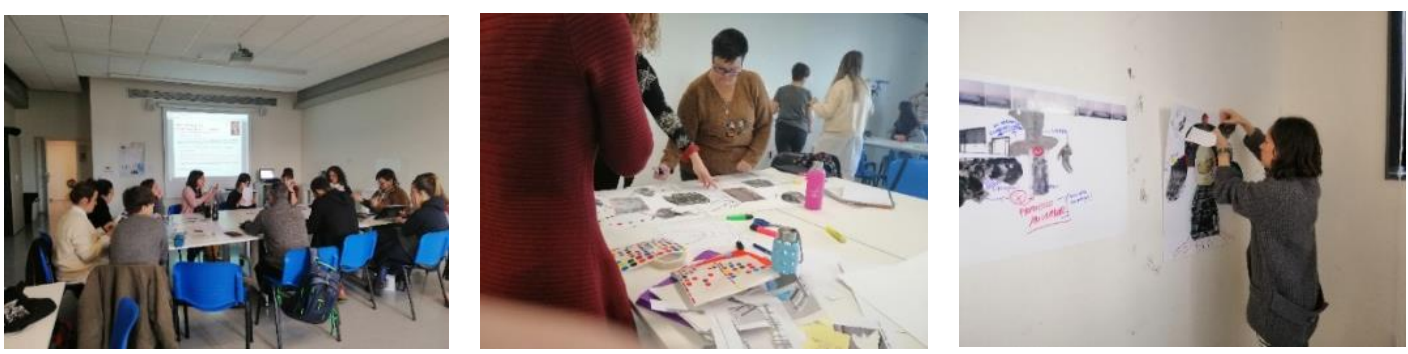

Figura. 1,2 y 3. Autores (2020) Imágenes del proceso del taller.

\subsection{Resultados y evaluación del proceso: Cartografiar los lugares de trabajo que pretendemos habitar.}

El grupo de innovación docente que participó en el taller está formado por trabajadores administrativos, alumnado y profesorado de expresión plástica, expresión musical, trabajo social y pedagogía. Se realizaron seis cartografías en torno a la pregunta ¿Cómo nos relacionamos con los espacios en las facultades y que otras relaciones podríamos provocar? 

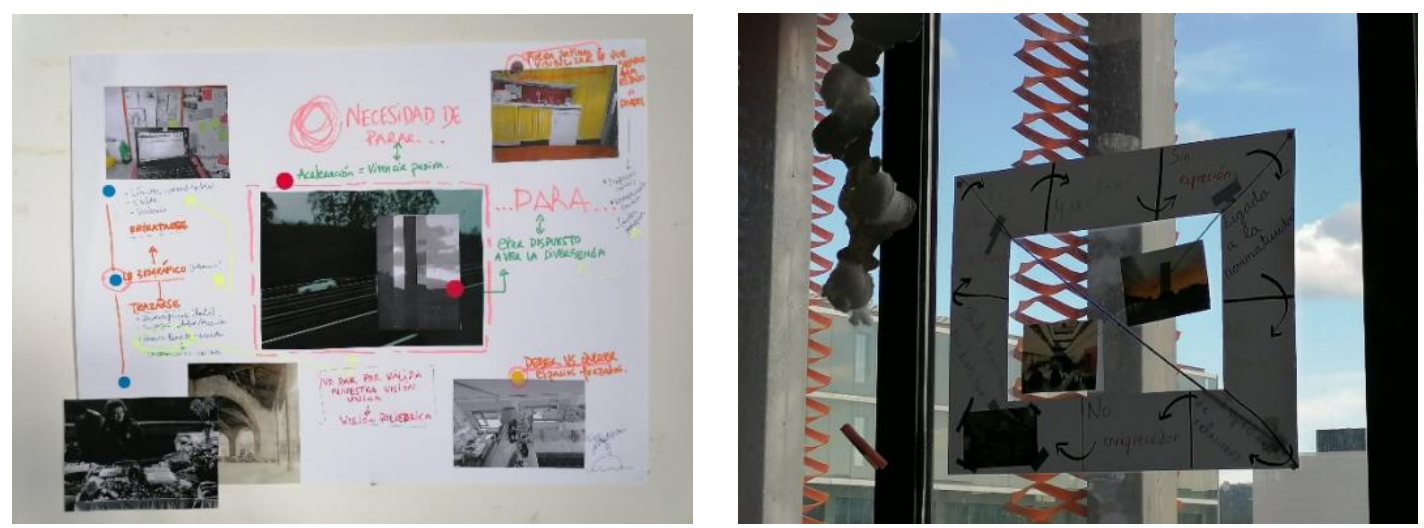

Figura 4 y 5. Autores (2020) Imágenes de cartografías realizadas por las participantes en el taller.

1) En la primera cartografía (Figura.4) se habla sobre sensaciones y necesidades respecto al trabajo y cómo el espacio de trabajo nos condiciona, nos retrata y nos traza, la huella que dejamos, el cómo habitamos nuestro lugar de trabajo, el sentimiento de pertenencia, el concepto de lo privado y lo público, lo simbólico o lo visible. Transmite mensajes cómo la necesidad de parar para estar dispuesto a ver las divergencias, la aceleración cómo una vivencia pasiva. El no dar por válida nuestra visión única lanzando una lanza a favor de la visión poliédrica. Y la necesidad vital por visibilizar lo que siempre ha estado, aceptando el cambio y la diversidad que ese cambio trae consigo.

2) La segunda cartografía (Figura. 5) visibiliza una especie de marco que a su vez se expone en la ventana generando un doble marco en donde mirar. La ventana representa el espacio arquitectónico de la Facultad de Educación de Bilbao donde habitan dos grandes patios que condicionan la funcionalidad del edificio. Estos dos espacios, según las autoras, son monótonos, están ligadas a la normatividad impidiendo las relaciones pedagógicas. Son espacios con falta de pertenencia que han sido pensados para transitar, pero no para habitar. 

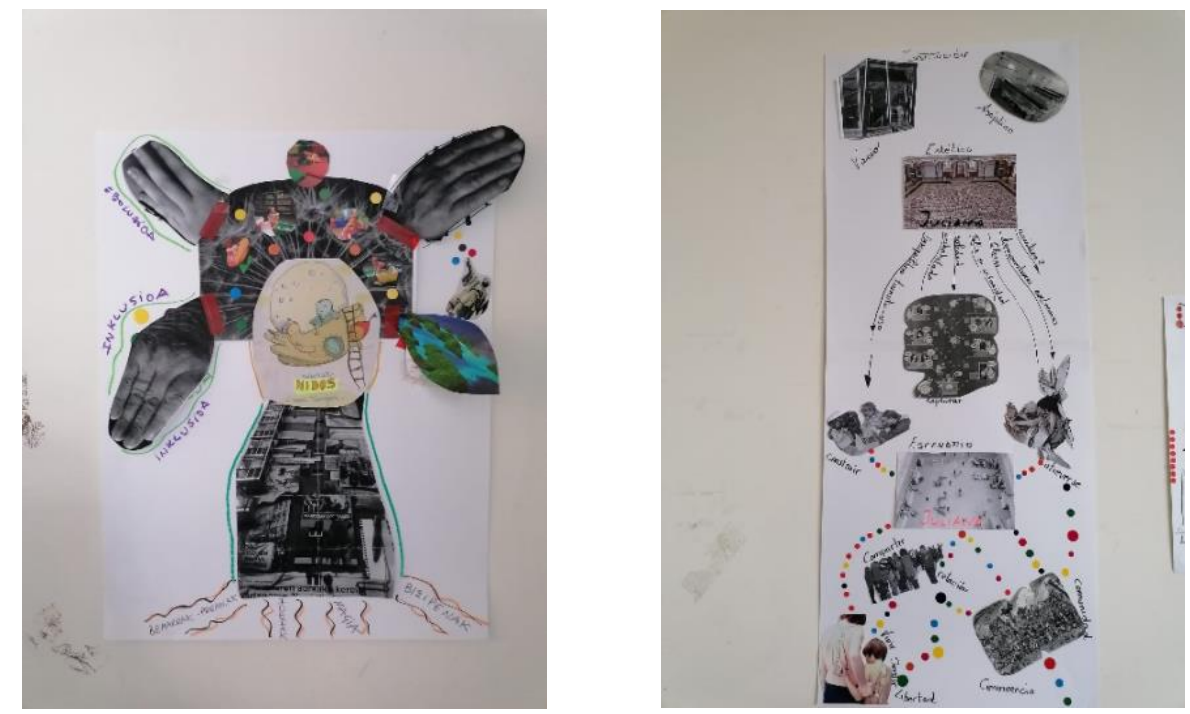

Figuras 6 y 7. Autores (2020) Imágenes de cartografías realizadas por las participantes en el taller.

3) La tercera cartografía (Figura. 6) tiene una forma orgánica, a modo de flor cuyos pétalos son manos que cobijan y abrazan las necesidades que debería de tener un espacio de trabajo que se dedica a la formación. La cartografía se centra en qué otras realidades podríamos provocar en nuestro lugar de trabajo. Donde las necesidades del colectivo, las ideas, la magia y las vivencias deberían de estar acompañadas por espacios donde sentirte protegido/a, donde lo corpóreo y lo afectivo deberían de ser prioridades esenciales, donde la relación con la naturaleza debería estar en un primer plano y el espacio destinado al trabajo debería "adecuar nidos a los nuevos tiempos".

4) La cuarta cartografía (Figura. 7) muestra cómo sienten las autoras el lugar de trabajo. La institución la describen como una estética vacía y aséptica donde el espacio causa una sensación de deshabitado, de soledad, de falta de intimidad, abundantes olores, temperaturas extremas, una acústica inapropiada, un desequilibrio entre el tránsito y el uso que se le da al espacio. Todo ello les lleva a explorar nuevos escenarios posibles donde deberíamos poder atrevernos a construir un nuevo espacio pedagógico donde predomine el compartir, la comunidad y la relación pedagógica. La necesidad de habitar el espacio desde los afectos resignificando el espacio social de la Facultad. 

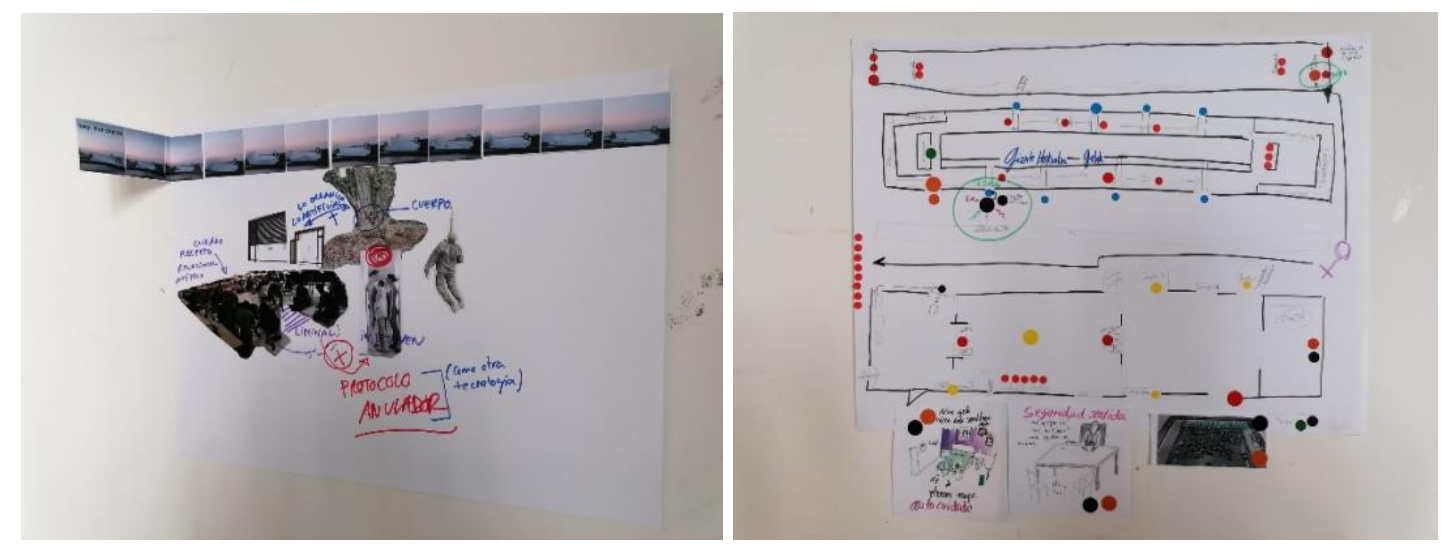

Figuras 8 y 9. Autores (2020) Imágenes de cartografías realizadas por las participantes en el taller.

5) La quinta cartografía (Figura. 8) relaciona lo artificial con lo arquitectónico y lo orgánico con el cuerpo, una relación en constante convivencia o en constante desacuerdo en los territorios pedagógicos. El protocolo de las instituciones es anulador y no deja espacios para que esa convivencia se dé, dejando entrever que el cuidado y el respeto es una relación atípica en los espacios de nuestras facultades.

6) Finalmente la sesta cartografía (Figura. 9) visibiliza los recorridos espaciales del interior del edificio cuestionando en base a qué prioridades se ha construido el mismo. Las múltiples parcelas y las aulas cerradas crean una seguridad asfixiante y las relaciones de poder son unidireccionales donde el profesor manda, predica y los docentes atienden sin que el espacio de juego al diálogo y a la convivencia.

Todas las cartografías atienden a la relación que se genera entre espacio y cuerpo y cómo el diseño de la arquitectura condiciona las relaciones pedagógicas dejando entrever la necesidad de espacios más habitables, más corporizados, con un componente afectivo que ayude a la comunicación de los distintos miembros del colectivo pedagógico. A través de las cartografías, con el empleo de las imágenes pudimos trazar y dibujar las líneas para poder dialogar y reflexionar sobre cómo resignificar el espacio social de la facultad. 


\section{Conclusión: Ventanas hacia una relación pedagógica más orgánica}

A modo de conclusión presentamos un foto-ensayo que deriva de la reflexión sobre cómo nos relacionamos con los espacios en las facultades y qué otras relaciones podríamos provocar a partir de esta reflexión conjunta.

A partir del taller cartográfico que desarrollamos, realizamos una serie de fotografías que mostrasen una mirada personal del proceso de elaboración y resultado de las cartografías. Estas imágenes han sido el punto de partida del foto-ensayo y a partir de las cuales hemos ido construyendo la narrativa visual que aportamos en el siguiente apartado de este trabajo.

El tema de esta narrativa visual se centra en el espacio (arquitectónico) y la relación (pedagógica). A través de las imágenes indagamos en preguntas y reflexiones que emergieron del taller. La composición es subjetiva e interpretativa y busca desde la indagación artística llegar a una reflexión investigadora que aporte conocimiento. Este ejercicio creativo pretende ser parte de un proceso investigador que aporte desde la visualidad otros aspectos a tener en cuenta. El proyecto tiene entre una de sus finalidades la reflexión estética, y este ejercicio precisamente pretende hacer esta reflexión desde estrategias o modos de mirar y pensar, estéticos.
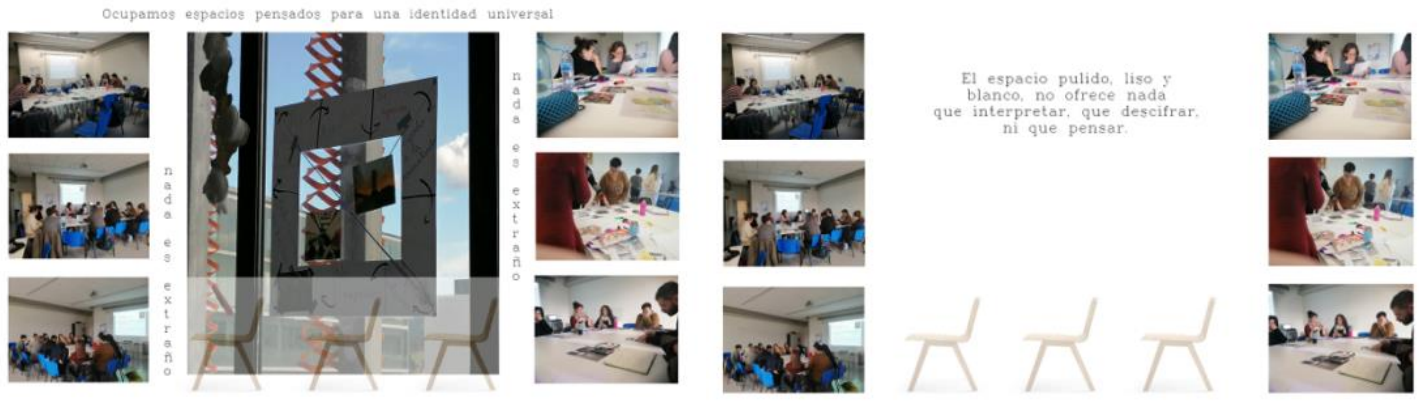

Figura 10 y 11 . Autoras (2020) Foto-Ensayo realizado a partir de las imágenes extraídas por las investigadoras durante el taller. 


\section{Tercio Creciente}

DOI: https://dx.doi.org/10.17561/rtc.extra4.5743 Investigación

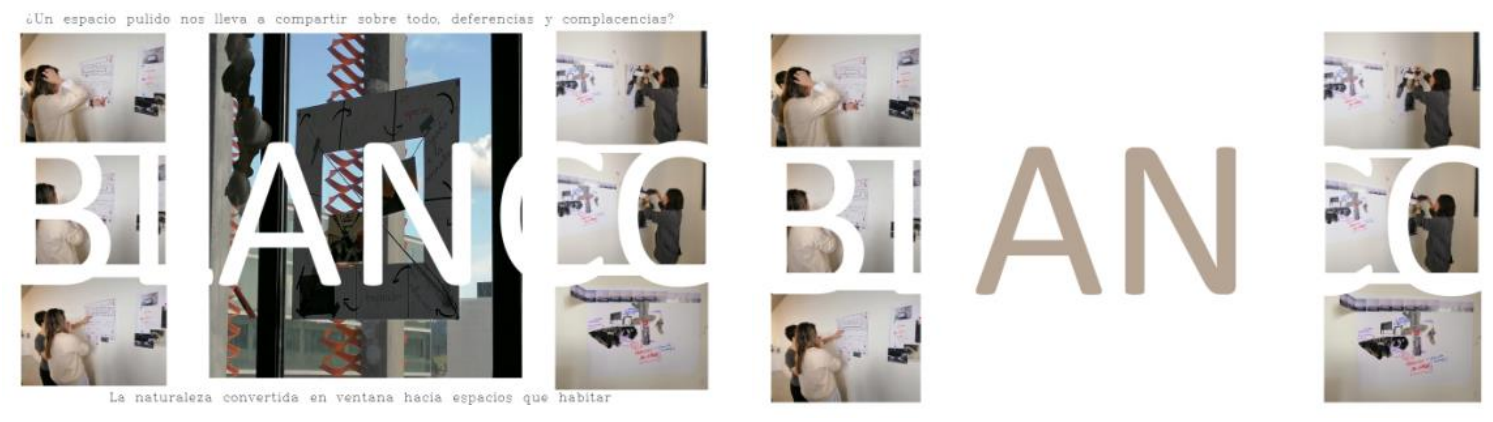

Figura 12 y 13. Autoras (2020) Foto-Ensayo realizado a partir de las imágenes extraídas por las investigadoras durante el taller.
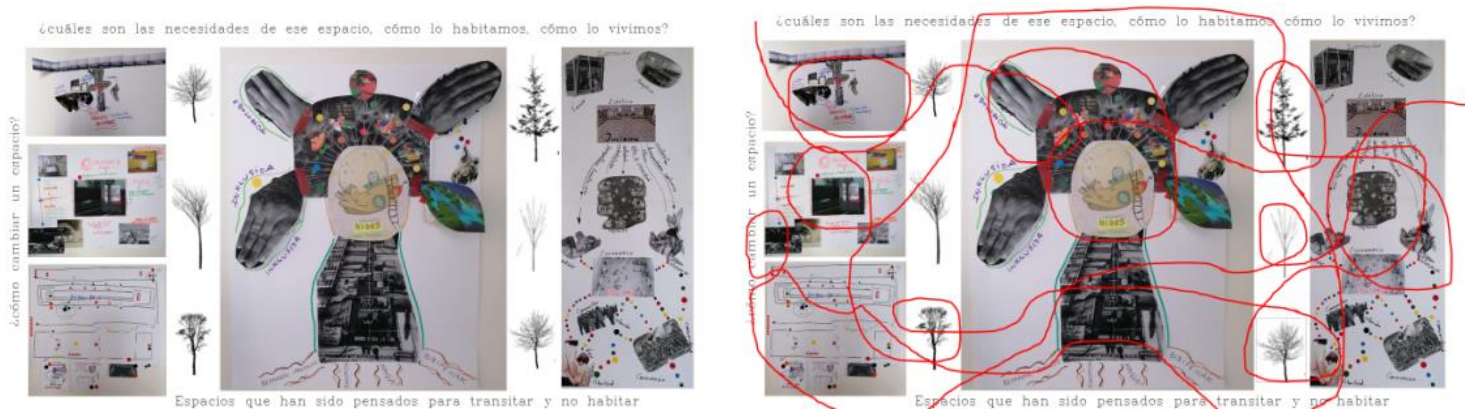

Figura 14 y 15. Autoras (2020) Foto-Ensayo realizado a partir de las imágenes extraídas por las investigadoras durante el taller.

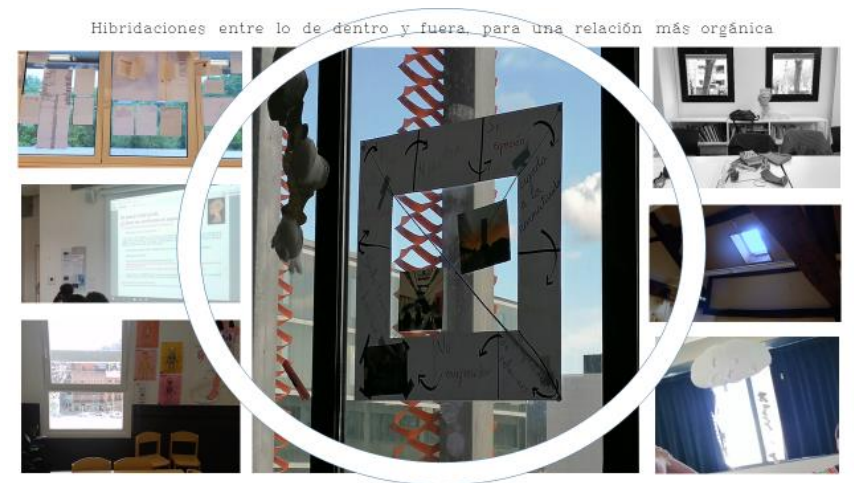

Figura 14 y 15. Autoras (2020) Foto-Ensayo Realizado a partir de las imágenes extraídas por las investigadoras durante el taller. 
El propósito del taller cartográfico y del foto-ensayo como fuentes no disciplinares en investigación:

surge de la necesidad de desarrollar la capacidad crítica del sujeto participante, que fomenta a través del encuentro y el diálogo entre formas de expresión diversas, claves para enriquecer la cimentación cultural y multidisciplinar necesaria en los procesos educativos y de formación en ámbitos creativos" (Fernández y Genet, 2017, p. 53).

Coincidimos con Roldán y Marín que "cada una de las fotografías que configuran un foto-ensayo $y$, sobre todo, las interrelaciones que establecen unas imágenes con otras, van centrando sucesivamente las posibles interpretaciones y significados hasta conformar con suficiente claridad una idea o razonamiento" (2012, p. 76) Estas interrelaciones que se generan entre las imágenes de nuestro foto-ensayo nos traslada al taller realizado, pero también a nuestras aulas y lugar de trabajo donde la distribución arquitectónica, la distribución del mobiliario, las ventanas, el disponer de materiales como cuerdas, telas, ramas o simplemente de espacio físico para mover los cuerpos genera un modo de aprender más orgánico, corporeizado (Ellsworth, 2005), menos encorsetado donde el docente y el profesorado se relacionan y dialogan en un espacio más democrático, frágil, vulnerable y afectivo.

En todo momento está presente la relación pedagógica que se generó en el taller cartográfico, en las observaciones colectivas del mismo y las conclusiones o miradas múltiples que han surgido en la realización del foto-ensayo. Rescatamos las palabras de Hernández en torno a la relación pedagógica (2011),

tener como referente la relación pedagógica nos lleva, por el contrario, a prestar atención a cómo se posibilitan los encuentros en los que se comparte subjetividades y saberes. Esto hace que el espacio de clase sea por encima de todo, un encuentro de sujetos en torno a experiencia de conocer y compartir." (Hernández, 2011, p. 7).

\section{Referencias}

Calderón, N. y Hernández, F. (2019) La investigación artística; Un espacio de conocimiento disruptivo en las artes y en la universidad. Ed. Octaedro.

Deleuze, G. y Guattari, F. (2008). Rizoma. Valencia: Pre-textos. 
Eisner, W. E. \& Barone, T. (2006) Arts-Based Educational Research en J.L Green, G.Camilli y P:B Elmore (Eds.) Hand book of complementary methods in education research (pp. 95-109) Mahwah, New Yersey: AERA.

Ellsworth, E. (2005) Posiciones en la enseñanza. Diferencia, pedagogía y el poder de la direccionalidad (trd.: L. Trafí Prats) Madrid: Akal.

Fernández, A.M y Genet, R. (2017) La mirada expandida: el fotoensayo como herramienta en arquitectura. Sobre №3 (pp.39-54).

Gutiérrez-Cabello, A. y Aberasturi-Apraiz, E. (2019). Cartografías en torno a los tránsitos en el aprender de docentes en educación infantil y primaria. Educatio siglo XXI: Revista de la Facultad de Educación, № 37, (2). http://dx.doi.org/10.6018/j/387031

Hernández, F.; Sancho, J.M (2015) Pensar la docencia universitaria desde las relaciones pedagógicas. REIRE, revista d'innovació i recerca en educación, (pp.4-10). DOI: 10.1344/reire2015. 8.28211

Marín, R. (2005). Investigación en educación artística: temas, métodos y técnicas de indagación sobre el aprendizaje y la enseñanza de las Artes y cultura visual. Granada: Universidad de Granada y Universidad de Sevilla.

Marín, R. y Roldán, J. (2008) Imágenes de las miradas en el museo. Un fotoensayo descriptivo-interpretativo a partir de H.Daumier, en R. de la Calle y R. Huerta (Eds.) Mentes sensibles. Investigar en Educación y Museos (pp. 97-108), Valencia: Publicacions de la Universitat de València. http://dx.doi.org/10.6018/j/387031

Marín, R. y Roldán, J. (2010) Photo essays and photographs in visual arts-based educational research en International Journal of Education though Art, 6:1, (pp. 723).

Pallasmaa, J. (2006). Los ojos en la piel. La arquitectura y los sentidos. Gustavo Gili.

Peña, N. (2014) La fotografía como imagen sensorial. Recuerdos invisibles para una interpretación visual. Terciocreciente, №5 (pp.27-36).

St. Pierre, E. A. (1997). Methodology in the fold and the irruption of transgressive data. International Journal of Qualitative Studies in Education, 10(2), 175-189. https://doi.org/10.1080/095183997237278 
DOI: https://dx.doi.org/10.17561/rtc.extra4.5743 Investigación

Lugares y No Lugares para la creación Diciembre 2020 